\title{
Supporting Information: \\ Ordinary and hot electroluminescence from single-molecule devices: controlling the emission color by chemical engineering
}

\author{
Michael C. Chong ${ }^{1}$, Lydia Sosa-Vargas ${ }^{2}$, Hervé Bulou ${ }^{1}$, Alex Boeglin ${ }^{1}$, \\ Fabrice Scheurer $^{1}$, Fabrice Mathevet ${ }^{2, *}$, and Guillaume Schull ${ }^{1, *}$ \\ ${ }^{1}$ Institut de Physique et Chimie des Matériaux de Strasbourg, \\ UMR 7504 (CNRS - Université de Strasbourg), 67034 Strasbourg, France \\ ${ }^{2}$ Institut Parisien de Chimie Moléculaire, Sorbonne Universités, \\ UPMC Université Paris 06, CNRS, 75005 Paris, France
}

${ }^{2}$ fabrice.mathevet@upmc.fr; ${ }^{1}$ guillaume.schull@ipcms.u-strasbg.fr

\section{CONTENTS}

S1 - Synthesis of porphyrins.

S2 - TD-DFT calculations.

S3 - Mirror symmetry between R- and B- bands. 


\section{S1 - Synthesis of porphyrins.}

All anhydrous solvents used were obtained from a Pure Solv ${ }^{\text {TM }}$ Solvent Purification System. The inert atmosphere utilized can refer to either argon or nitrogen gas although in most reactions nitrogen was used. TLC analysis was carried out on Merck aluminium-backed silica gel 60 F254 coated plates. Column chromatography was performed at room temperature

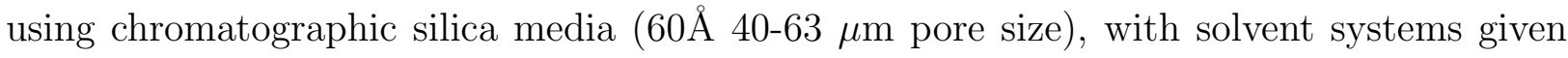
as volume ratios. ${ }^{1} \mathrm{HNMR}$ spectra were recorded at $300 \mathrm{MHz}$ on a Bruker spectrometer in $\mathrm{CD} 2 \mathrm{Cl} 2$ or $\mathrm{d} 8$-toluene. The chemical shifts were calibrated by the solvent residual peaks and the positions of the peaks are reported in ppm. J-values are given in hertz. Proton decoupled ${ }^{13} \mathrm{C}$ NMR spectra were recorded on the same spectrometer.

\section{Synthesis of materials}

The 5,5"-dibromo-2,2':5',2"-ter-thiophene (DBrTT) and 5,15-(diphenyl)-10,20-(dibromo) porphyrin $\left(\mathrm{Br}_{2}-\mathrm{DPPH}_{2}\right)$ are commercially available and were purchased from Sigma-Aldrich and from Frontier Scientific respectively. The synthetic procedures for both 5-phenyl-10,20dibromoporphyrin $\left(\mathrm{Br}_{2}-\mathrm{MPPH}_{2}\right)$ and 5,15-di-naphthalen-2-yl-10,20-dibromoporphyrin $\left(\mathrm{Br}_{2}\right.$ $\left.\mathrm{DNPH}_{2}\right)$ are adapted from previous works $[1,2]$ and described in the general scheme shown below. Both precursors 1 and $\mathbf{2}$ were synthesised following previously reported procedures[3, 4] whilst $\mathbf{3}$ and $\mathbf{4}$ were commercially available from Sigma-Aldrich as were most of the reagents used.
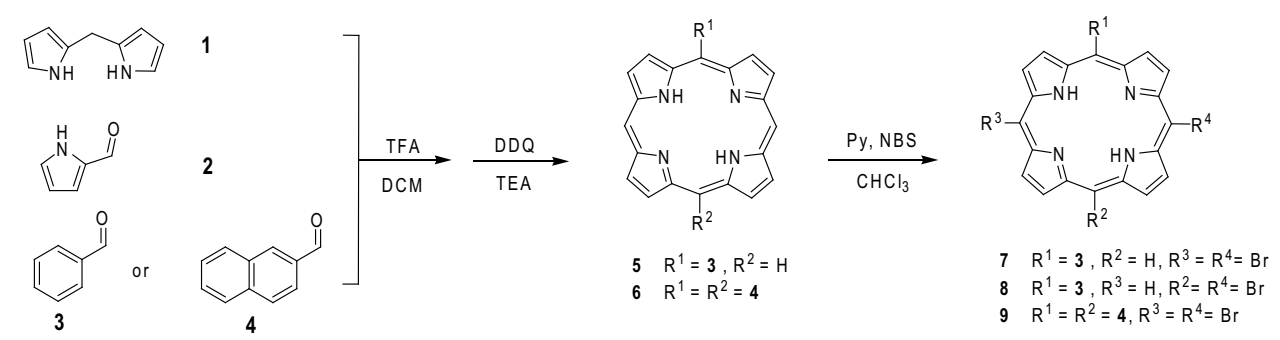

Figure S1. General synthetic route followed for the synthesis of the $\mathrm{Br}_{2}-\mathrm{MPPH}_{2}$ and $\mathrm{Br}_{2}-\mathrm{DNPH} 2_{2}$ porphyrin chromophores. 
Synthesis of 5-phenylporphyrin(5)

Dipyrromethane (0.29 g, $2 \mathrm{mmol})$, pyrrole-2-carbaldehyde (0.38 g, $4 \mathrm{mmol}$ ) and benzaldehyde $(0.2 \mathrm{~mL}, 2 \mathrm{mmol})$ are dissolved in anhydrous dichloromethane $(1.0 \mathrm{~L})$ in an aluminium foil-covered flask. The solution is bubbled with N2 whilst stirring for 15 minutes. To this solution, trifluoroacetic acid $(0.07 \mathrm{~mL}, 0.9 \mathrm{mmol})$ is added dropwise and the reaction is left to stir for 4 hours under and inert atmosphere. 2,3-Dichloro-5,6-dicyano-1,4-benzoquinone $(1.3 \mathrm{~g}, 5.7 \mathrm{mmol})$ are then added rapidly under a stream of nitrogen and left to stir for an additional hour. The reaction is terminated by the addition of triethylamine $(2 \mathrm{~mL})$. The reaction mixture is then concentrated under reduced pressure to $50 \mathrm{~mL}$ and then passed through a silica-gel plug to obtain a red-purple filtrate. The solvent is removed under reduced pressure and the crude product is purified by column chromatography using a 1:1 (Petroleum ether/DCM) mixture as eluent. The desired product is isolated from the diphenyl porphyrin by-product and the solvent removed under reduced pressure to give a red-purple crystalline solid (28.5 mg, 8\%). 1H NMR (300 MHz, $\left.\mathrm{CD}_{2} \mathrm{Cl}_{2}\right) \delta 10.38(\mathrm{~s}, 2 \mathrm{H})$, $10.31(\mathrm{~s}, 1 \mathrm{H}), 9.58-9.52(\mathrm{~m}, 4 \mathrm{H}), 9.46(\mathrm{~d}, J=4.7 \mathrm{~Hz}, 2 \mathrm{H}), 9.11(\mathrm{~d}, J=4.6 \mathrm{~Hz}, 2 \mathrm{H}), 8.32$ - $8.23(\mathrm{~m}, 2 \mathrm{H}), 7.84(\mathrm{dd}, J=5.0,2.0 \mathrm{~Hz}, 3 \mathrm{H}), 3.63(\mathrm{~s}, 2 \mathrm{H})$.

Synthesis of 5,15-dinaphthalen-2-yl-porphyrin (6)

Following the procedure for 5, dipyrromethane $(0.20 \mathrm{~g}, 1.4 \mathrm{mmol})$ and 2-naphthaldehyde $(0.21 \mathrm{~g}, 1.4 \mathrm{mmol})$ are dissolved in anhydrous dichloromethane $(1.0 \mathrm{~L})$. Trifluoroacetic acid $(0.06 \mathrm{~mL}, 0.8 \mathrm{mmol})$ is added dropwise via syringe, stirring for 4 hours under an inert atmosphere. The 2,3-dichloro-5,6-dicyano-1,4-benzoquinone (0.37 g, $1.7 \mathrm{mmol})$ is added and the mixture stirred for another hour. Triethylamine $(2.0 \mathrm{~mL})$ is added before removing the solvent under reduced pressure. The title compound is isolated from the tri-substituted porphyrin by-product by column chromatography using a 2:1 (Petroleum ether/DCM) mixture as eluent as a purple crystalline solid (175 mg, $22 \%$ yield). ${ }^{1} \mathrm{H} \mathrm{NMR} \mathrm{(300} \mathrm{MHz,}$ $\left.\mathrm{CD}_{2} \mathrm{Cl}_{2}\right) \delta 10.39(\mathrm{~s}, 1 \mathrm{H}), 9.46(\mathrm{~d}, J=4.7 \mathrm{~Hz}, 2 \mathrm{H}), 9.12(\mathrm{~d}, J=4.7 \mathrm{~Hz}, 2 \mathrm{H}), 8.75(\mathrm{~s}, 1 \mathrm{H})$, $8.48(\mathrm{~d}, J=8.3 \mathrm{~Hz}, 1 \mathrm{H}), 8.30(\mathrm{~d}, J=8.4 \mathrm{~Hz}, 1 \mathrm{H}), 8.28-8.22(\mathrm{~m}, 1 \mathrm{H}), 8.21-8.11(\mathrm{~m}, 1 \mathrm{H})$, $7.83-7.69(\mathrm{~m}, 2 \mathrm{H}), 3.60(\mathrm{~s}, 2 \mathrm{H})$. 
5-phenylporphyrin (0.03 g, $0.08 \mathrm{mmol})$ is dissolved in anhydrous chloroform $(100 \mathrm{~mL})$ and cooled to $0{ }^{\circ} \mathrm{C}$ in an ice bath. To this solution, pyridine $(0.07 \mathrm{~mL}, 0.85 \mathrm{mmol})$ is added and stirred for 15 minutes under an inert atmosphere. N-bromosuccinimide (0.028 $\mathrm{g}, 0.16 \mathrm{mmol}$ ) is added in a single portion under a nitrogen stream and stirred for a further 20 mins. The reaction is removed from the ice bath, acetone $(10 \mathrm{~mL})$ is added and the solvent is then evaporated under reduced pressure. Recrystallisation of the crude product using dichloromethane/methanol and exhaustive washing with methanol yielded a dark purple crystalline powder $(0.073 \mathrm{~g}, 87 \%$ yield $)$. The di-brominated product is obtained as a 2:1(approx) mixture of the desired title compound 10,20 (trans) and 10, 15 (cis)-dibromoporphyrin.

Synthesis of 5,15-di-naphthalen-2-yl-10,20-dibromoporphyrin (9)

Following the procedure above, 5,15-di-naphthalen-2-yl-porphyrin (0.15 g, $0.3 \mathrm{mmol})$, pyridine $(0.25 \mathrm{~mL}, 3 \mathrm{mmol})$, N-bromosuccinimide $(0.1 \mathrm{~g}, 0.6 \mathrm{mmol})$ in anhydrous chloroform $(100 \mathrm{~mL})$. Reaction is left to stir for 2 hours under an inert atmosphere. Acetone $(10 \mathrm{~mL})$ is added and the solvent is removed under reduced pressure. Recrystallisation of the crude product using dichloromethane/methanol and exhaustive washing with methanol yielded a dark purple crystalline powder $(0.147 \mathrm{~g}, 77 \%$ yield $) .{ }^{1} \mathrm{H}$ NMR $(300 \mathrm{MHz}$, Toluene-d8) $\delta 9.52$ $(\mathrm{d}, J=4.8 \mathrm{~Hz}, 4 \mathrm{H}), 8.65(\mathrm{~d}, J=4.9 \mathrm{~Hz}, 4 \mathrm{H}), 8.34(\mathrm{~s}, 2 \mathrm{H}), 8.10(\mathrm{~d}, J=8.4 \mathrm{~Hz}, 2 \mathrm{H}), 7.98$ - $7.88(\mathrm{~m}, 3 \mathrm{H}), 7.88-7.78(\mathrm{~m}, 3 \mathrm{H}), 7.54-7.44(\mathrm{~m}, 4 \mathrm{H}), 2.75(\mathrm{~s}, 2 \mathrm{H})$. 


\section{S2 - TD-DFT calculations.}

The electronic structure calculations were performed using Density Functional Theory (DFT) as implemented in the Gaussian 09 software [5]. The geometries of the three macrocycles were optimized in vacuo using the B3LYP functional and the 6-31G(d,p) basis set. The 32 lowest singlet excitations were first determined in the Time Dependent DFT (TDDFT) methodology using the same functional and basis set. For all three fused porphyrins, using the larger $6-311+\mathrm{G}(\mathrm{d}, \mathrm{p})$ basis set lowered the first excitation energy by $0.01 \mathrm{eV}$ only.

The effect of two additional ter-thiophene groups was thus gauged by repeating all the calculations with the smaller basis set. However, fused-DNP showed no significant change in its lowest excitation energy while fused-DPP ended up being $0.03 \mathrm{eV}$ below the experimental value. Only for fused-MPP did the energy of the first excited singlet improve by $0.08 \mathrm{eV}$, remaining $0.07 \mathrm{eV}$ above the experimental value, the same margin by which our calculations underestimate the transition energy for ter-thiophene bound fused-DNP.

\begin{tabular}{|c|c|c|c|c|c|c|}
\hline & fMPP & btT-fMPP & fDPP & btT-fDPP & $\mathrm{fDNP}$ & btT-fDPP \\
\hline $6-311+\mathrm{G}(\mathrm{d}, \mathrm{p})$ & 1.82 & - & 1.50 & - & 1.20 & \\
\hline $6-31 \mathrm{G}(\mathrm{d}, \mathrm{p})$ & 1.83 & 1.75 & 1.51 & 1.48 & 1.21 & 1.21 \\
\hline Experimental & - & $1.68 \pm 0.06$ & - & $1.51 \pm 0.04$ & - & $1.28 \pm 0.06$ \\
\hline
\end{tabular}

In all cases, the dihedral angle of the ter-thiophene groups were found to be close to $49^{\circ}$ as defined by four linked carbon atoms. Furthermore, it was found that the occupied and the virtual orbitals involved in the first transition were all centered on the fused-porphine cycles. Therefore, while the thiophene groups have a slight inductive effect on the electronic density distribution over the macro-cycles, the lowest singlet excitations are proper to the porphyrin moieties and thus these are the transition energies listed in Fig. $2 \mathrm{C}$ of the manuscript. 


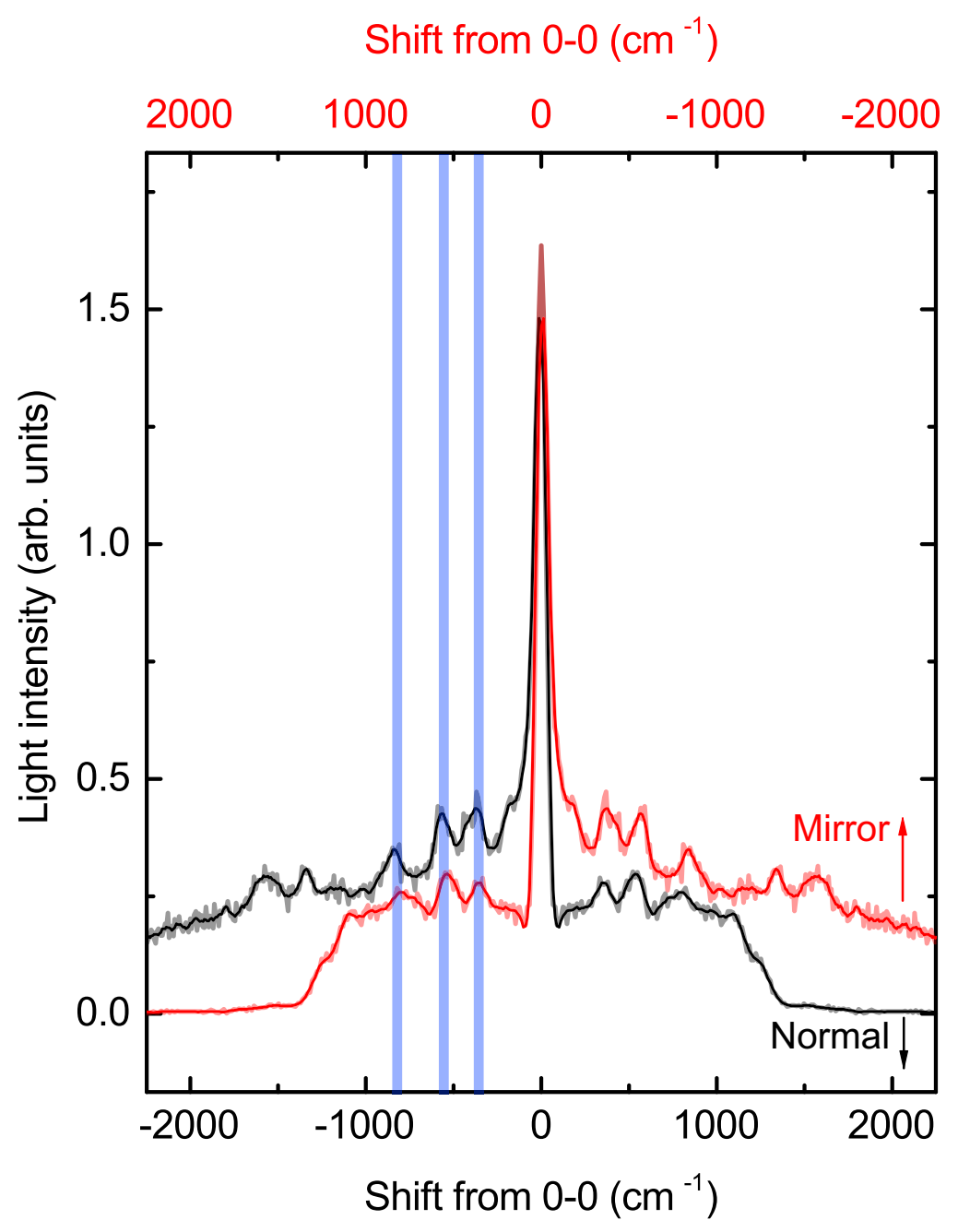

Figure S2. Mirror symmetry between R- and B- bands (a) Light emission spectrum of a suspended fused-MPP (in black) and its mirror image (in red) with respect to the 0-0 line ( $V=$ $1.8 \mathrm{~V})$. The blue vertical lines highlight the strong resemblance between the energy dispersion of the vibronic peaks on both side of the 0-0 line.

[1] C. Ryppa, O. Senge, S.S. Hatscher, E. Kleinpeter, P. Wacker, U. Schilde, A. Wiehe, Chem. Eur. J. 11, 3427-3442 (2009).

[2] D. E. Chumakov, A.V. Khoroshutin, A.V. Anisimov, K.I. Kobranov, Chem. Heterocycl. Com. 
45, 259-283 (2009)

[3] E. V. Vinogradova, Y. Y. Enakieva, Y. Gorbunova, A. Y. Tsivadze, Prot. Met. Phys. Chem., 45, 529-534 (2009)

[4] D. K. Dogutan, M. Ptaszek, J. S. Lindsey, J. Org.Chem, 72, 5008-5011 (2007).

[5] Gaussian 09, Revision B.01, M. J. Frisch, G. W. Trucks, H. B. Schlegel, G. E. Scuseria, M. A. Robb, J. R. Cheeseman, G. Scalmani, V. Barone, B. Mennucci, G. A. Petersson, H. Nakatsuji, M. Caricato, X. Li, H. P. Hratchian, A. F. Izmaylov, J. Bloino, G. Zheng, J. L. Sonnenberg, M. Hada, M. Ehara, K. Toyota, R. Fukuda, J. Hasegawa, M. Ishida, T. Nakajima, Y. Honda, O. Kitao, H. Nakai, T. Vreven, J. A. Montgomery, Jr., J. E. Peralta, F. Ogliaro, M. Bearpark, J. J. Heyd, E. Brothers, K. N. Kudin, V. N. Staroverov, T. Keith, R. Kobayashi, J. Normand, K. Raghavachari, A. Rendell, J. C. Burant, S. S. Iyengar, J. Tomasi, M. Cossi, N. Rega, J. M. Millam, M. Klene, J. E. Knox, J. B. Cross, V. Bakken, C. Adamo, J. Jaramillo, R. Gomperts, R. E. Stratmann, O. Yazyev, A. J. Austin, R. Cammi, C. Pomelli, J. W. Ochterski, R. L. Martin, K. Morokuma, V. G. Zakrzewski, G. A. Voth, P. Salvador, J. J. Dannenberg, S. Dapprich, A. D. Daniels, O. Farkas, J. B. Foresman, J. V. Ortiz, J. Cioslowski, and D. J. Fox, Gaussian, Inc., Wallingford CT, 2010. 